\title{
BMJ Open Prevalence of peritonitis and mortality in patients with ESKD treated with chronic peritoneal dialysis in Africa: a systematic review
}

\author{
Ikechi G Okpechi (10 , ${ }^{1,2,3}$ Udeme Ekrikpo, ${ }^{1,4}$ Mothusi W Moloi, ${ }^{1,5}$ \\ Jean Jacques Noubiap, ${ }^{6}$ Ugochi S Okpechi-Samuel, ${ }^{7}$ Aminu K Bello ${ }^{3}$
}

To cite: Okpechi IG, Ekrikpo U, Moloi MW, et al. Prevalence of peritonitis and mortality in patients with ESKD treated with chronic peritoneal dialysis in Africa: a systematic review. BMJ Open 2020;10:e039970. doi:10.1136/ bmjopen-2020-039970

- Prepublication history and additional material for this paper is available online. To view these files, please visit the journal online (http://dx.doi.org/10. 1136/bmjopen-2020-039970).

Received 30 April 2020 Revised 29 November 2020 Accepted 07 December 2020

Check for updates

(C) Author(s) (or their employer(s)) 2021. Re-use permitted under CC BY-NC. No commercial re-use. See rights and permissions. Published by BMJ.

For numbered affiliations see end of article.

Correspondence to

Dr Ikechi G Okpechi; ikechi.okpechi@uct.ac.za

\section{ABSTRACT}

Objective The aim of this study was to report the prevalence of peritonitis and mortality in patients with end-stage kidney disease (ESKD) treated with chronic peritoneal dialysis (PD) in Africa.

Design Systematic review.

Setting Africa.

Participants Patients with ESKD in Africa.

Interventions $P D$ in its varied forms.

Primary and secondary outcomes PD-related peritonitis rate (primary outcome), time-to-discontinuation of PD, mortality.

Data sources Four databases, including PubMed, Embase, Web of Science and Africa Journal Online were systematically searched from 1 January 1980 to 31 December 2019.

Eligibility criteria Studies conducted in Africa reporting peritonitis rate and mortality in patients treated with PD.

Data extraction and synthesis Two reviewers extracted and synthesised the data using Microsoft Excel. The quality of included data was also assessed.

Results We included 17 studies from seven African countries representing 1894 patients treated with PD. The overall median age was 41.4 years (IQR: $38.2-44.7$ ) with a median time on PD of 18.0 months (17.0-22.6). An overall median peritonitis rate of $0.75(0.56-2.20)$ episodes per patient-year (PPY) was observed and had declined with time; peritonitis rate was higher in paediatric studies than adult studies (1.78 (1.26-2.25) vs $0.63(0.55-1.87)$ episodes PPY). The overall median proportion of deaths was $21.1 \%$ (16.2-25.8). Culture negative peritonitis was common in paediatric studies and studies that reported combined outcomes of continuous ambulatory PD and automated PD. Both 1-year and 2-year technique survival were low in all studies $(83.6 \%$ and $53.0 \%$, respectively) and were responsible for a high proportion of modality switch.

Conclusions Our study identifies that there is still high but declining peritonitis rates as well as low technique and patient survival in PD studies conducted in Africa. Sustained efforts should continue to mitigate factors associated with peritonitis in patients with ESKD treated with PD in Africa.

PROSPERO registration number CRD42017072966.
Strengths and limitations of this study

- Extensive literature search of Medline, Embase, Web of Science and Africa Journal online with independent screening of all abstracts and eligible full-text publications by two investigators.

- Assessment of study quality and extensive data extraction on peritonitis rate, proportion of deaths, technique and patient survival from each study.

- Significant heterogeneity in populations, peritonitis rates and proportion of deaths precluded the use of meta-analysis to further summarise the data.

- Reported deaths were not usually linked to infectious peritonitis but included all deaths occurring in patients treated with peritoneal dialysis.

- There was only one prospective study and quality of reporting of outcomes was not optimal across studies.

\section{INTRODUCTION}

Despite having several advantages over haemodialysis (HD) including cost, preservation of residual renal function, improved quality of life, greater independence and better initial survival, the utilisation of peritoneal dialysis (PD) as a modality for kidney replacement therapy (KRT) in Africa is limited. ${ }^{1}$ Data from the South African Renal Registry show that of the 10744 patients who have received KRT in South Africa in 2017, only $11.2 \%$ were on PD while $71.5 \%$ were on HD and $17.3 \%$ were kidney transplant recipients. ${ }^{2}$ Due to several reasons, including the high cost or unavailability of PD fluids, unavailability of PD catheters, patient unwillingness, reimbursement of physicians and high rates of peritonitis and other PD catheter-related infections, chronic PD is unavailable in many countries in Africa. ${ }^{13}$ A number of studies from Africa report that low socioeconomic status, ${ }^{4}$ low level of education, ${ }^{45}$ dwelling in informal housing ${ }^{6}$ and lack of electricity and water 


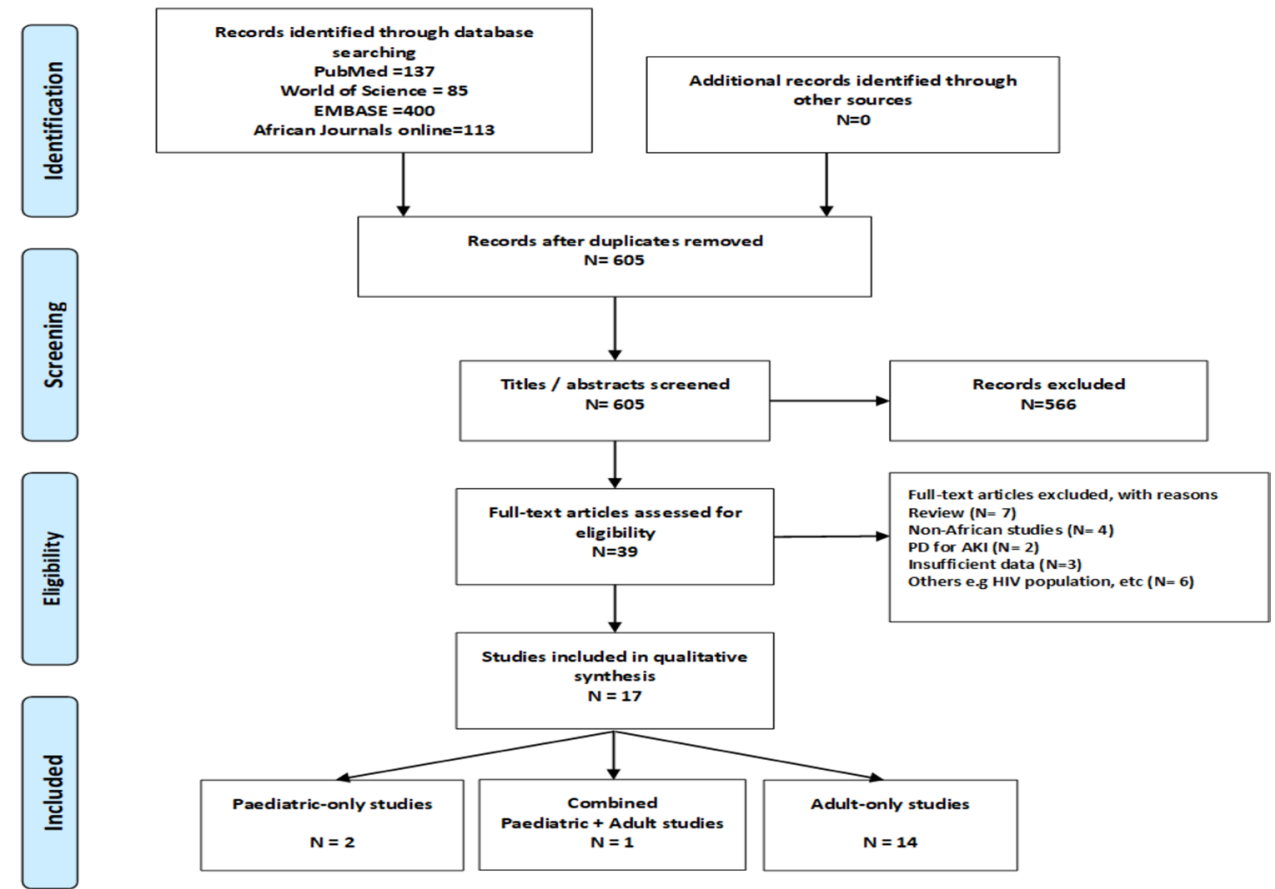

Figure 1 Preferred Reporting Items for Systematic Reviews and Meta-Analyses flow diagram. AKI, acute kidney injury; PD, peritoneal dialysis.

supply to households ${ }^{47}$ are associated with increased rates of peritonitis; this is thought to influence the reduced utilisation of PD in the continent. For these reasons, $\mathrm{PD}$ is frequently offered to highly motivated, educated and financially stable patients with acceptable levels of personal hygiene, ${ }^{389}$ such as in the South African public sector where KRT is still rationed. The International Society of Peritoneal Dialysis (ISPD) recommends for peritonitis rates to be under 0.5 episodes per year at risk, ${ }^{10}$ however, studies from Africa often show much higher peritonitis rates leading to an increased change in KRT modality, technique failure and mortality. We conducted this systematic review to estimate the prevalence of peritonitis and mortality in African patients with end-stage kidney disease (ESKD) treated with PD. Although this study is not designed to assess measures to prevent peritonitis, we hope it will show that peritonitis rates have been reducing in Africa with time and the $\mathrm{PD}$ can be an option for KRT in the continent.

\section{METHODS}

\section{Selection of eligible studies, types of studies and sources of information}

The Preferred Reporting Items for Systematic Reviews and Meta-Analysis 2009 guidelines ${ }^{11}$ was the framework for reporting this review (see online supplemental table 1 and figure 1). The study protocol was registered in the International Prospective Register of systematic reviews and has been published. ${ }^{12}$ We searched PubMed, Embase, Web of Science and Africa Journal Online for relevant studies on peritonitis related to the treatment of patients with ESKD treated with PD. The searches were limited to studies performed in Africa and published from 1 January 1980 to 31 December 2019. Key search terms were: 'peritoneal dialysis', 'peritonitis', 'Africa' with a filter to include all African countries (PubMed, Embase and Web of Science search strategies are shown in online supplemental tables 2-4). Further, we used controlled vocabularies synonyms to identify related terms. Individual country names for all African countries were also included in the search.

\section{Search strategy/identification of studies}

Two authors (MWM and JJN) independently assessed all abstracts for eligibility. In situations of disagreements between the two reviewers, a third reviewer (IGO) arbitrated for eligibility. JJN assessed all the abstracts in French. Studies included were observational studies (cross-sectional studies, prospective observational studies and cohort studies) reporting data on the prevalence of peritonitis and mortality among children and/or adults with ESKD treated with PD in Africa. There were no restrictions to studies based on age, language, sample size or type of PD used (continuous ambulatory PD (CAPD), automated PD (APD) or nightly intermittent PD (NIPD)). However, the following exclusion criteria were applied: (1) case reports, case-control studies and review articles, (2) studies conducted among populations of African origin residing outside of Africa, (3) duplicates or similar data from the same centre and by the same authors which included data from the excluded study (eg, Abu-Aisha $e t$ $a l^{13}$ and Jellouli et al), (4) studies from which the prevalence of PD-related peritonitis cannot be determined and whose full data could not be accessed even after request from the authors, (5) studies describing PD outcomes in 


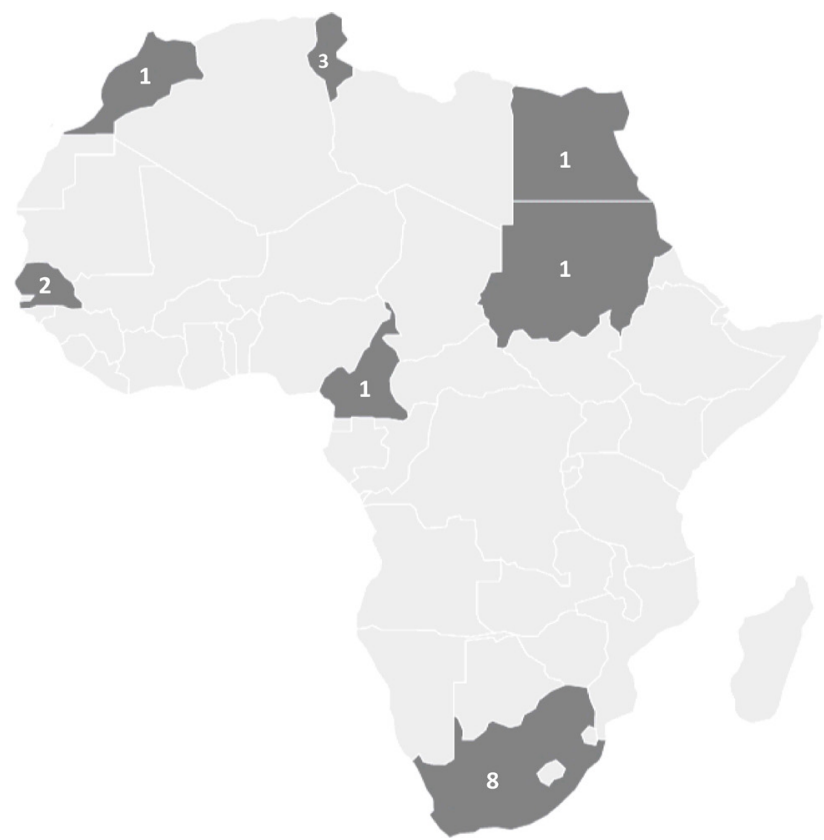

Figure 2 African countries with number of studies included in this study.

a specific ESKD population (eg, HIV, diabetics and so on) or focusing on specific organisms or types of peritonitis (eg, fungal peritonitis, encapsulating peritoneal sclerosis and so on), (6) studies on other types of infections in patients treated with PD (eg, exit site infection, tunnel infection and so on) and (7) studies of PD outcomes for acute kidney injury (AKI).

\section{Data extraction and assessment of study quality}

We grouped studies based on the type of PD used (CAPD only or CAPD+APD/NIPD or APD only) and based on the population studied (paediatric only, adult only or paediatric+adult). Two investigators (IGO and UE) independently extracted data; discrepancies between investigators were resolved through discussion until consensus was reached. Data extracted included first author name, year of publication, country of study origin, sample size of the study, gender proportions in the study population, mean age, mean duration of patients on PD, number of peritonitis episodes, peritonitis rate (reported as episodes/ patient-year), number of deaths and types of organisms causing peritonitis. We also recorded the proportion of patients changing modality, transplanted, recovering kidney function as well as 1-year and 2-year technique and patient survival (if provided). Assessment of quality in individual studies was performed independently by two reviewers (IGO and UE), using an adapted quality assessment tool from a previous prevalence study ${ }^{14}$ to evaluate the quality of individual studies by assessing selection bias, study design, data collection method, statistical analysis and withdrawals. The quality of individual studies was rated as high $(8-10)$, medium $(5-7)$ or low $(<5)$ (see online supplemental tables 5 and 6 ).

\section{Statistical analysis}

Microsoft Excel (Redmond, Washington, USA) was used to compile extracted data. Due to heterogeneity of the study population and reporting, a meta-analysis was not carried out. However, we pooled the reported data and for each variable of interest, we calculated the median and IQR. The primary outcome was the peritonitis rate and the proportion of deaths reported from the studies during the study period. Secondary outcomes included proportion of modality switch to HD, patients who had transplants and reported 1-year and 2-year technique and patient survival. Studies were grouped into adult studies, paediatric studies, CAPD only studies, CAPD+APD/NIPD studies and APD-only studies. The results were presented as reported percentages, rates and as overall/group median (IQR).

\section{Patient and public involvement}

Patients and/or the public were not involved in the design, conduct, reporting or dissemination plans of this research.

\section{RESULTS}

\section{Demographic features of included studies}

Seventeen studies were included in this review representing studies from seven countries (Cameroon, ${ }^{15}$ Egypt, ${ }^{8}$ Morocco, ${ }^{16}$ Senegal, $^{7}{ }^{17}$ South Africa, ${ }^{4} 59$ 18-22 Sudan $^{23}$ and Tunisia ${ }^{24-26}$ ) (figure 2). The overall sample size for the studies was 1894 with a median sample of 85 (IQR: 62-152). The median proportion of men in all the studies was 59\% (IQR: 52-61) with an overall median age of 41.4 years (IQR: 38.2-44.7). The median time on PD was 18.0 months (IQR: 17.0-22.6); the median time on PD was shorter in paediatric studies compared with adult studies (12.6 months vs 18.0 months). There was only one $(5.9 \%)$ study from South Africa that had a prospective design, ${ }^{20} 14 / 17(82.4 \%)$ studies were conducted in adults, 45 7-9 15-21 2426 two studies were in paediatric patients ${ }^{2225}$ and one study from Sudan included combined data from paediatric and adult patients on $\mathrm{PD} .{ }^{23}$ The types of PD reported were: CAPD (nine studies), $458151618-21$ CAPD+APD/NIPD (seven studies) 791722232526 and APD (one study) ${ }^{24}$ (tables 1 and 2).

\section{Peritonitis rates and organisms causing peritonitis}

Over time (1980-2019), the reported peritonitis rate was observed to be declining. The highest peritonitis rate was 2.72 episodes per patient-year (PPY), the lowest was 0.33 episodes PPY with an overall median peritonitis rate of 0.75 (IQR: 0.56-2.20) episodes PPY for all studies. The median peritonitis rate for studies published in the $1980 \mathrm{~s}$ and 1990s was 2.71 (IQR: 2.58-2.72) episodes PPY and had improved to a median of 0.60 (IQR: 0.55-0.82) episodes PPY for studies published in the 2000s. Other groups also showed improved peritonitis rates from 1980 to 2019. The median peritonitis rates in studies focused on adults and children were 0.63 (IQR: 0.55-1.87) and 1.78 


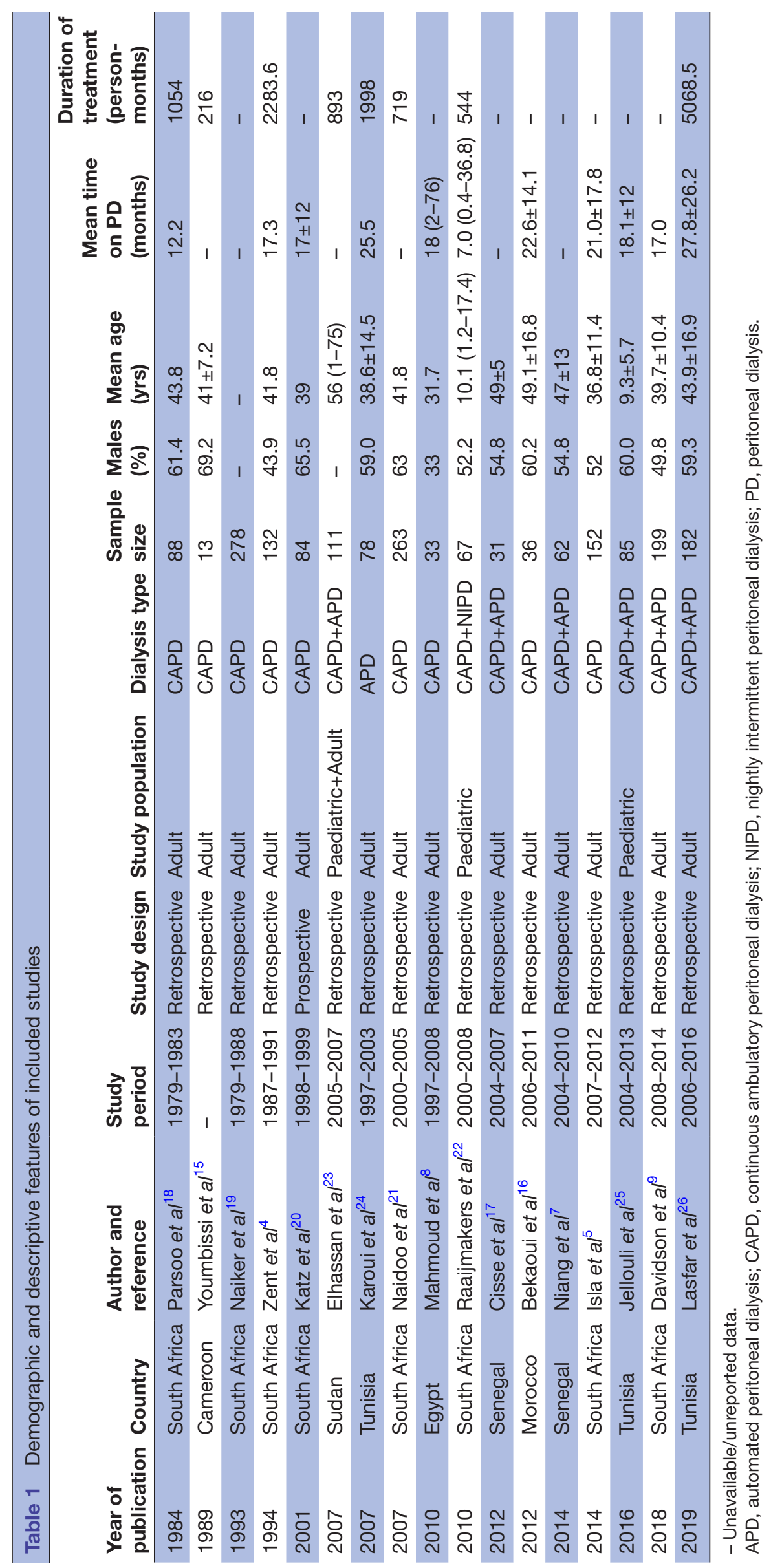




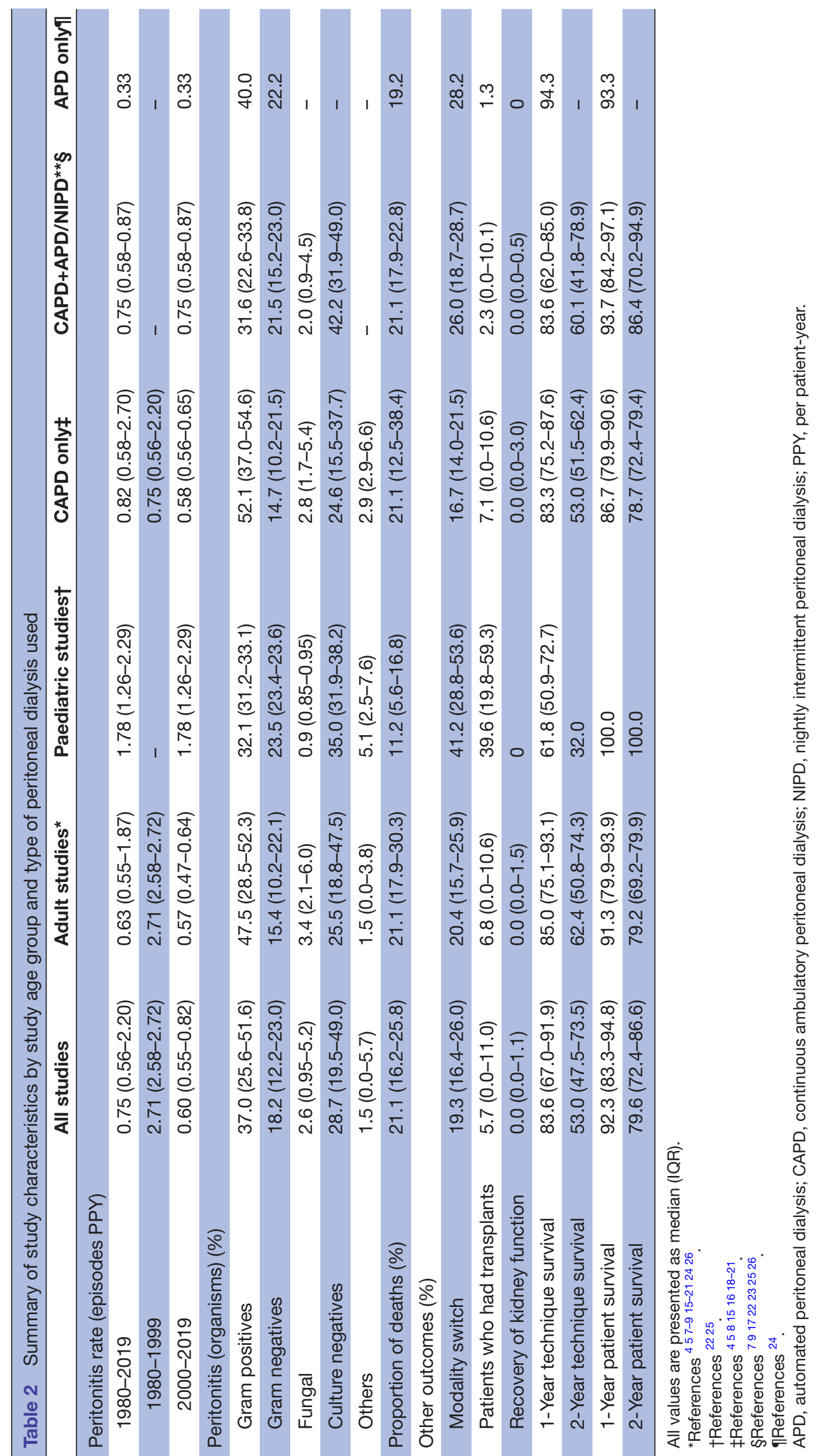


(IQR: 1.26-2.25) episodes PPY, respectively. The median peritonitis rate was also higher in studies reporting use of CAPD (0.82 (IQR: 0.58-2.7)) than in those reporting the outcomes of patients on CAPD combined with APD/ NIPD (0.68 (IQR: 0.52-0.87) episodes PPY, tables 2 and $3)$. In the lone study that described patient outcomes when treated with APD only, the peritonitis rate was 0.33 episodes PPY.

Gram-positive bacteria (GPB) were the most common cause of peritonitis with an overall median of $37.0 \%$ (IQR: 25.6-51.6); the prospective study from South Africa had the highest reporting of GPB as the cause of peritonitis $(85.3 \%) .{ }^{20}$ Culture-negative peritonitis was highest in paediatric studies (35.0\% (IQR: 31.9-38.2)) and studies that combined CAPD with APD/NIPD (42.2\% (IQR: 31.9-49.0)). In three studies, more than half of the reported cultures yielded no growth (culture-negative). (tables 2 and 4 ).

\section{Mortality, technique and patient survival}

Two studies reported no deaths for the duration of their studies. In studies reporting deaths, the lowest was $8.3 \%$ and the highest $39.2 \%$. The median proportion of deaths from all the studies was 21.1\% (IQR: 16.2-25.8). The median proportion of deaths was lower in the two paediatric studies (11.2\% (IQR: 5.6-16.8)) compared with the studies in adults (21.1\% (IQR: 17.9-30.3)). Nine studies provided information on technique survival; overall median 1-year and 2-year techniques survival was 83.6\% (IQR: 67.0-91.9) and 53.0\% (47.5-73.5), respectively. The lowest technique survival was from a paediatric study (1-year-40.0\% and 2-year-32.0\%). For studies providing data on patient survival, median 1-year and 2-year patient survival was $92.3 \%$ (IQR: 83.3-94.8) and $79.6 \%$ (IQR: 72.4-86.6), respectively. Only one study showed $100 \%$ patient survival during their study duration (tables 2 and 3 ).

\section{Other outcomes-modality switch, transplants and recovered kidney function}

Modality switch to HD and proportion of patients who had transplants were highest in the paediatric studies with median values of $41.2 \%$ (IQR: 28.8-53.6) and 39.6\% (IQR: 19.8-59.3), respectively. Patients treated only with CAPD had the lowest proportion of modality switch to HD (16.7\% (IQR: 14.0-21.5)). The overall proportion of patients who had transplants was 5.7\% (IQR: 0.0-11.0) and three studies reported $0 \%$ transplant due to unavailability at their centre. ${ }^{5717}$ For studies that reported recovery of kidney function, this ranged from as low as $0.6 \%^{26}$ to $9.5 \%^{20}$ (tables 2 and 5 ).

\section{DISCUSSION}

This systematic review has used published data from 17 studies, over a period spanning four decades, to report on some important observations on peritonitis rates, mortality and other outcomes such as modality switch and survival in patients treated with PD in Africa. Our study has demonstrated the lack of utilisation of chronic PD as a KRT modality in the African continent. Eight of the 17 studies $(47.1 \%)$ that met inclusion were from South Africa with six studies (35.3\%) from North African countries, two $(11.8 \%)$ from West Africa and one $(5.9 \%)$ from Central Africa. The significance of this becomes even more apparent when consideration is given to reports from the South African Renal Registry that shows that chronic PD represents only $11.2 \%$ of all KRT in that country. ${ }^{2}$ Although PD may be more cost-effective than $\mathrm{HD},{ }^{27}$ various factors have accounted for low PD utilisation in Africa, including poor infrastructure, lack of PD fluids, unavailability of catheters and high peritonitis rates often leading to modality switch to HD. ${ }^{347}$

Even though we showed that peritonitis rates in PD in Africa has been on the decline since the 1980s, it nevertheless remains higher than current recommendations of the ISPD. ${ }^{10}$ Results from the Peritoneal Dialysis Outcomes and Practice Patterns Study (PDOPPS) involving 7051 adult patients treated with PD across seven developed countries showed crude peritonitis rate to be 0.28 episodes PPY ${ }^{28}$ Lower peritonitis rate was reported if the centres used more APD, used antibiotics at catheter insertion, had longer PD training duration or used topical exit-site mupirocin or aminoglycoside ointment. ${ }^{28}$ Although it is unclear what the practice patterns of the centres are in the studies included in this research, however, the one study that reported outcomes in patients treated with APD demonstrated the lowest peritonitis rate. ${ }^{24}$ Sociodemographic factors were highlighted in several of the studies included in our research and appear to play a major role in peritonitis rates in Africa. The reduction in peritonitis rate with time may possibly be related to use of the Y-set and twin bag connection systems ${ }^{729}$ and improved selection of patients with housing, electricity, running water and other amenities to PD. ${ }^{9}$

The bacteriology of peritonitis in this study is comparable to findings from other studies that have shown a predominance of Gram-positive organisms. The PDOPPS study reported similar microbiology of peritonitis across all countries, except in Thailand, where Gram-negative and culture-negative peritonitis were more common. Culture-negative peritonitis was very high in many studies that were included in our research and represented over $50 \%$ of culture reports from three studies. This may be suggestive of poor sampling and culture methods and could lead to inappropriate treatment with antibiotics. A better understanding of PD effluent culture sampling and adherence to international recommendations on diagnostic methods may reduce rates of culture-negative peritonitis.

Peritonitis has also been demonstrated to be associated with technique failure, all-cause, cardiovascular and infection-related mortality in patients treated with PD. ${ }^{30} 31$ This relationship between peritonitis and mortality can explain the reduction in the proportion of deaths seen in our study which followed the same decline as peritonitis 


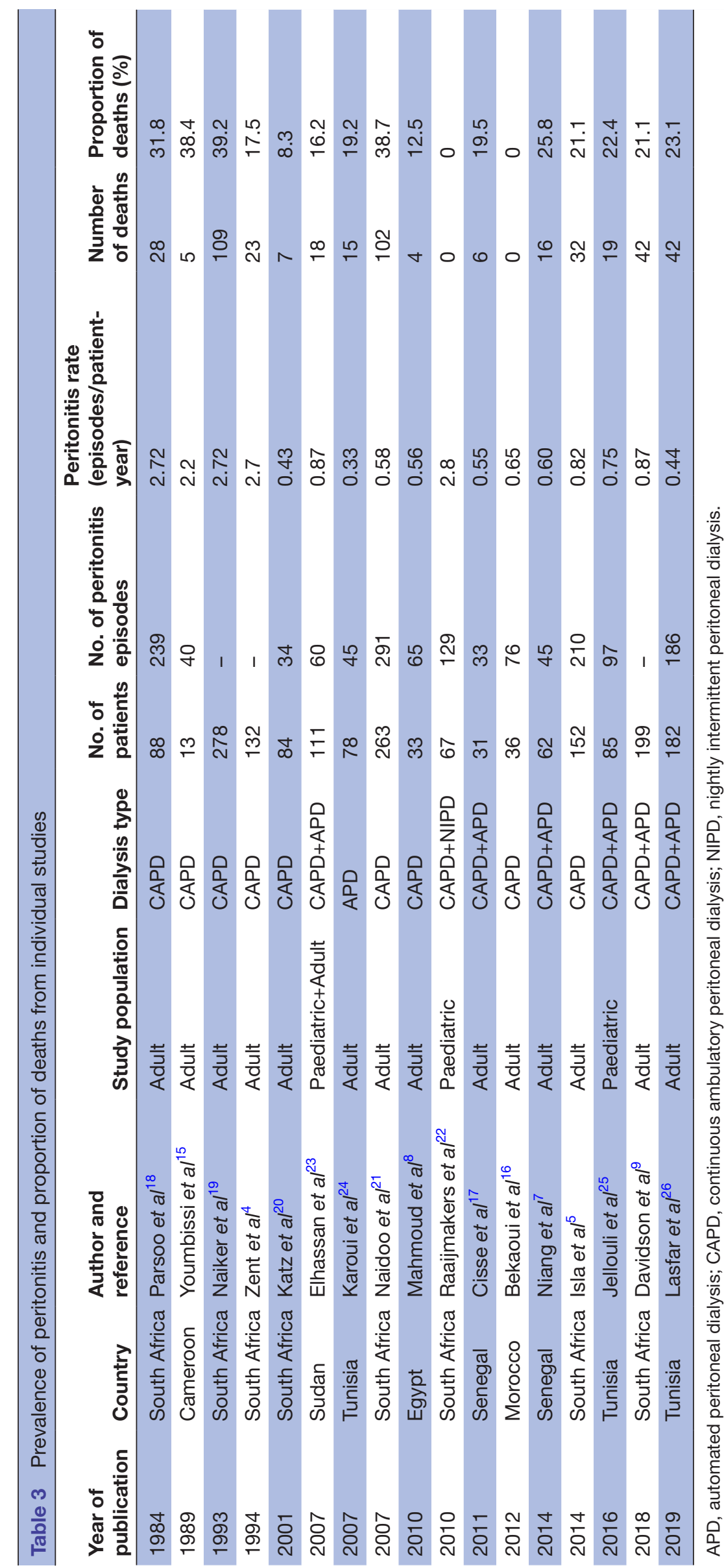


Table 4 Organisms causing peritonitis from individual studies

\begin{tabular}{|c|c|c|c|c|c|c|c|c|}
\hline $\begin{array}{l}\text { Year of } \\
\text { publication }\end{array}$ & Country & $\begin{array}{l}\text { Author and } \\
\text { reference }\end{array}$ & $\begin{array}{l}\text { Dialysis } \\
\text { type }\end{array}$ & $\begin{array}{l}\text { Gram (+) } \\
\text { organisms } \\
(\%)\end{array}$ & $\begin{array}{l}\text { Gam (-) } \\
\text { organisms } \\
(\%)\end{array}$ & $\begin{array}{l}\text { Fungal } \\
(\%)\end{array}$ & $\begin{array}{l}\text { Culture } \\
\text { negative } \\
(\%)\end{array}$ & $\begin{array}{l}\text { Others } \\
(\%)\end{array}$ \\
\hline 1984 & South Africa & Parsoo et $a l^{18}$ & CAPD & 50.0 & 15.4 & 3.4 & 24.6 & 6.6 \\
\hline 1989 & Cameroon & Youmbissi et al ${ }^{15}$ & CAPD & 52.5 & 27.5 & 7.5 & 12.5 & 0 \\
\hline 1993 & South Africa & Naiker et al $^{19}$ & CAPD & - & - & - & - & - \\
\hline 1994 & South Africa & Zent et $a l^{4}$ & CAPD & - & - & - & - & - \\
\hline 2001 & South Africa & Katz et a $\left.\right|^{20}$ & CAPD & 85.3 & 11.8 & 0 & 0 & 2.9 \\
\hline 2007 & Sudan & Elhassan et $\left.a\right|^{23}$ & CAPD+APD & 6.7 & 13.3 & 0 & 53.3 & - \\
\hline 2007 & Tunisia & Karoui et $\mathrm{al}^{24}$ & APD & 40.0 & 22.2 & - & - & - \\
\hline 2007 & South Africa & Naidoo et $\left.a\right|^{21}$ & CAPD & 52.1 & 8.6 & 2.1 & 18.5 & 18.8 \\
\hline 2010 & Egypt & Mahmoud et $a l^{8}$ & CAPD & 24.0 & 8.0 & 6.0 & 49.0 & - \\
\hline 2010 & South Africa & Raaijmakers et al ${ }^{22}$ & CAPD+NIPD & 30.2 & 23.3 & 0.8 & 28.7 & 10.1 \\
\hline 2011 & Senegal & Cisse et $a l^{17}$ & CAPD+APD & 33.0 & 21.0 & 3.0 & 43.0 & 0 \\
\hline 2012 & Morocco & Bekaoui et al ${ }^{16}$ & CAPD & 56.6 & 37.7 & - & 26.3 & - \\
\hline 2014 & Senegal & Niang et $\mathrm{al}^{7}$ & CAPD+APD & 20.0 & 22.0 & 7.0 & 51.0 & 0 \\
\hline 2014 & South Africa & Isla et $\left.a\right|^{5}$ & CAPD & 19.6 & 14.7 & 1.5 & 62.3 & 2.9 \\
\hline 2016 & Tunisia & Jellouli et $\left.a\right|^{25}$ & CAPD+APD & 34.0 & 23.7 & 1.0 & 41.3 & 0 \\
\hline 2018 & South Africa & Davidson et al ${ }^{9}$ & CAPD+APD & 47.5 & 4.0 & 5.0 & 19.5 & 0 \\
\hline 2019 & Tunisia & Lasfar et $a^{26}$ & CAPD+APD & - & - & - & - & - \\
\hline
\end{tabular}

- Unreported data.

APD, automated peritoneal dialysis; CAPD, continuous ambulatory peritoneal dialysis; NIPD, nightly intermittent peritoneal dialysis.

rate over the study period. A number of other factors such as increasing age, presence of comorbidities such as diabetes and underlying cardiovascular disease, early pre-dialysis care and use of icodextrin have been shown to influence mortality in patients treated with PD. ${ }^{631-33}$ One study from a predominantly rural population in South Africa showed a near fivefold increase in all-cause mortality in diabetic patients treated with PD than nondiabetic patients treated with HD in the same centre. ${ }^{6}$ However, we think that the high proportion of deaths and low technique and patient survival may be related to high peritonitis rates as in many centres, the selection process for KRT usually excludes those with comorbidities. ${ }^{39}$ Although icodextrin use has been reported to be associated with reduction in mortality, ${ }^{32}$ there is limited availability of icodextrin for PD in Africa given the overall shortage of all PD fluids ${ }^{3}$ and very limited use of icodextrin was reported in only 3 of the 17 studies. ${ }^{7926}$ Although cost is a major reason for the limited use of icodextrin, there still needs to be significant financial support to make locally produced PD fluids available as these have shown comparable efficacies with commercially produced fluids in patients with AKI treated with PD in Africa. ${ }^{34} 35$

The outcome of children with ESKD in Africa is similar to those in adults given that the same prevalent sociodemographic factors are also applicable. ${ }^{36}$ Children with ESKD treated with PD may face several added challenges such as schooling, logistics of accessing treatment, underlying developmental problems, emotional and psychological issues. ${ }^{37}$ The peritonitis rates seen in children in our study were much higher than for adults and this could be the reason for the higher modality switch to HD in children than in adults. However, the proportion of deaths in children was not as high as in adults. The reason for this could be the higher proportion of children than adults who received a kidney transplant during the study period (39.6\% (19.8-59.3) and 6.8\% (0.0-10.6)), respectively.

Our study findings show that more still needs to be done to reduce the peritonitis rates from centres across the African continent. Improved patient and care provider education, increased implementation of ISPD guidelines regarding catheter insertion, collection of specimens for microbiology and appropriate use of antibiotics need to be strictly adhered to. Skills gained from the saving young lives programme, ${ }^{34}$ a partnership of four organisations: International Society of Nephrology, International Paediatric Nephrology Association (IPNA), ISPD and the Sustainable Kidney Care Foundation on acute PD in Africa, can be leveraged and transferred to chronic PD. These efforts may improve PD outcomes in the continent and increase utilisation of PD as a KRT modality in Africa. However, strong support from various national and regional governments is needed to sustain these efforts.

One of the reasons for a higher prevalence of peritonitis in paediatric age groups may be due to the lack of paediatric nephrologists in several African countries, as children with kidney disease are often treated by general paediatricians, nephrologists who treat adults or nurses. ${ }^{38}$ 


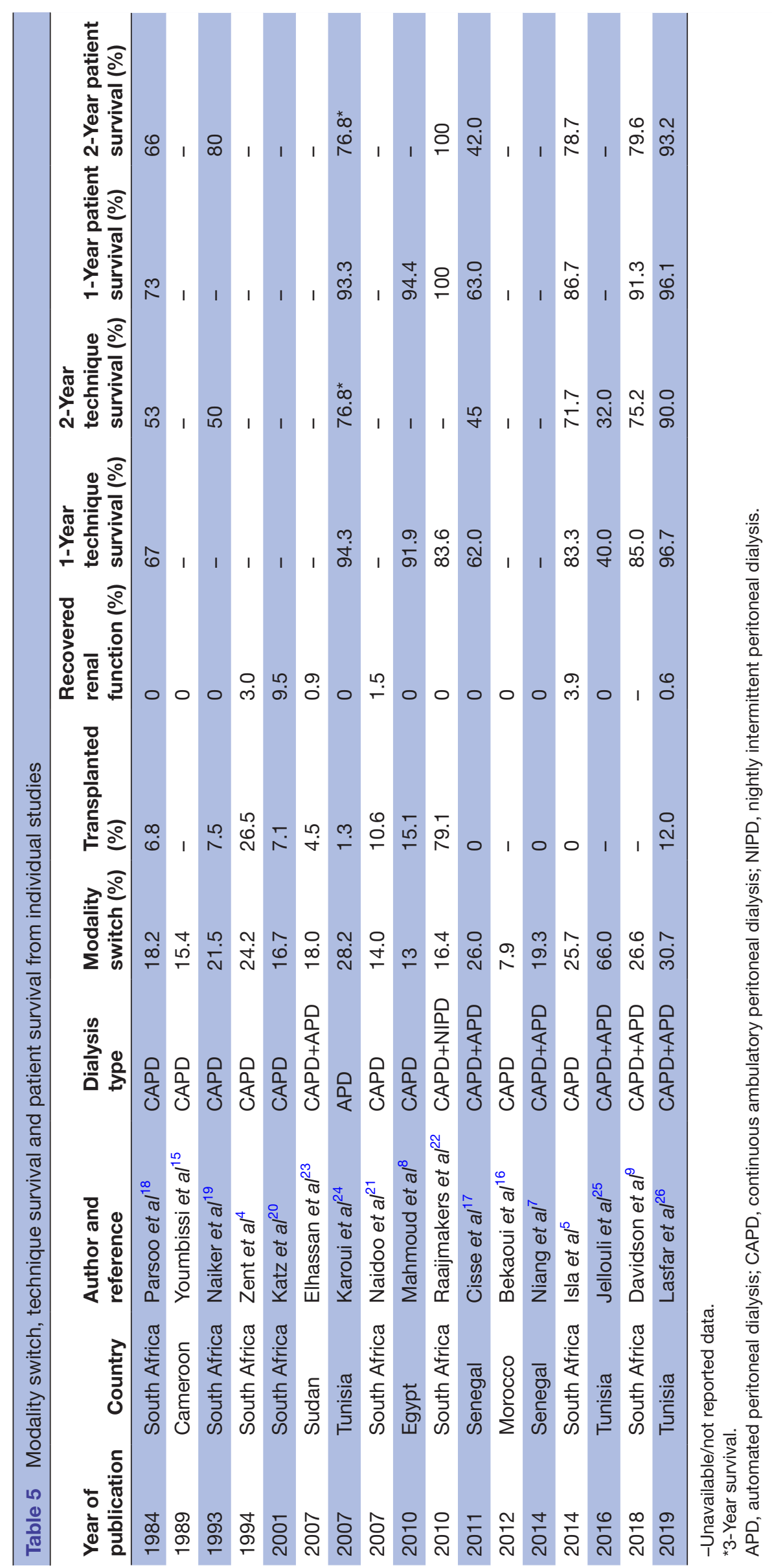


One survey conducted by the IPNA showed that $100 \%$ of respondents from Africa reported mild to severe shortages (72\% reported severe shortages) of paediatric nephrologists compared with $42 \%$ of respondents in Europe and $72 \%$ of respondents in Asia. ${ }^{39}$ Although the implications of such shortages on peritonitis rates in children have not been studied, it is possible that there is an association. Strategies to improve paediatric nephrology workforce in the continent should be further addressed.

Our study has some limitations. Most of the studies included had either a low or medium methodological quality. Some reasons for this include the low sample size and poor characterisation of sociodemographic features of patients included in the studies. Also, important clinical characteristics and outcomes were not reported appropriately and similarly across studies. For instance, although all studies reported peritonitis rate, not all provided the number of peritonitis episodes or the duration of treatment with PD. Furthermore, even though the proportion of deaths were reported, causes of death were not always provided to enable us to assess the relationship between infectious peritonitis and reported proportions of death. The Standardised Outcome in Nephrology Peritoneal Dialysis group recently recommended that inclusion of PD-related infection, cardiovascular disease, mortality, technique survival and life participation as the core outcome domains for PD. ${ }^{40}$ Finally, although we had intended to carry out a meta-analysis of our data, the heterogeneity across studies precluded it. Despite these limitations, our study has been able to show that peritonitis rates in PD, although still high, has been declining and reported on other important outcomes in patients treated with PD in Africa.

\section{CONCLUSION}

Our study shows high peritonitis rate, high proportion of mortality and low 1-2 year technique and patient survival in PD studies conducted in Africa over the past four decades. Although the peritonitis rates have been on a decline since the 1980s, they remain inappropriately higher than reports from other regions and what guidelines recommend. This suggests a need to sustain and improve ongoing efforts such as patient and staff education, improved selection of patients to PD, increase access to APD in selected patients, adherence to guidelines for sampling and treatment of peritonitis in order to mitigate factors associated with poor outcomes in patients with ESKD treated with chronic PD in Africa.

\section{Author affiliations}

${ }^{1}$ Division of Nephrology and Hypertension, University of Cape Town, Cape Town, South Africa

${ }^{2}$ Kidney and Hypertension Research Unit, University of Cape Town, Cape Town, Nigeria

${ }^{3}$ Department of Medicine, University of Alberta, Edmonton, Alberta, Canada

${ }^{4}$ Department of Medicine, University of Uyo, Uyo, Nigeria

${ }^{5}$ Department of Medicine, University of Botswana, Gaborone, Botswana
${ }^{6}$ Centre for Heart Rhythm Disorders, South Australian Health and Medical Research Institute (SAHMRI), University of Adelaide and Royal Adelaide Hospital, Adelaide, South Australia, Australia

${ }^{7}$ Department of Internal Medicine, National Hospital, Abuja, Nigeria

Correction notice This article has been corrected since it first published. The provenance and peer review statement has been included.

Contributors IGO and MWM contributed to conception of the work. IGO, UE, MWM and JJN contributed to systematic review and article evaluation. IGO and UE contributed to data analysis. IGO, UE, JJN and USO-S contributed to results interpretation. IGO, UE and AKB contributed to drafting the article. MWM, JJN, USO-S and AKB contributed to critical revision of the manuscript. All the authors contributed to final approval of the manuscript. All the authors fulfil the ICMJE criteria for authorship.

Funding This study has no external support and received no funding. JJNN is supported by a Postgraduate Scholarship from the University of Adelaide.

Map disclaimer The depiction of boundaries on this map does not imply the expression of any opinion whatsoever on the part of BMJ (or any member of its group) concerning the legal status of any country, territory, jurisdiction or area or of its authorities. This map is provided without any warranty of any kind, either express or implied.

Competing interests None declared.

Patient consent for publication Not required.

Ethics approval As this study is a systematic review based on published studies, ethical approval is not required.

Provenance and peer review Not commissioned; externally peer reviewed.

Data availability statement Data are available upon reasonable request from the corresponding author.

Supplemental material This content has been supplied by the author(s). It has not been vetted by BMJ Publishing Group Limited (BMJ) and may not have been peer-reviewed. Any opinions or recommendations discussed are solely those of the author(s) and are not endorsed by BMJ. BMJ disclaims all liability and responsibility arising from any reliance placed on the content. Where the content includes any translated material, BMJ does not warrant the accuracy and reliability of the translations (including but not limited to local regulations, clinical guidelines, terminology, drug names and drug dosages), and is not responsible for any error and/or omissions arising from translation and adaptation or otherwise.

Open access This is an open access article distributed in accordance with the Creative Commons Attribution Non Commercial (CC BY-NC 4.0) license, which permits others to distribute, remix, adapt, build upon this work non-commercially, and license their derivative works on different terms, provided the original work is properly cited, appropriate credit is given, any changes made indicated, and the use is non-commercial. See: http://creativecommons.org/licenses/by-nc/4.0/.

ORCID iD

Ikechi G Okpechi http://orcid.org/0000-0002-6545-9715

\section{REFERENCES}

1 Swanepoel CR, Wearne N, Okpechi IG. Nephrology in Africa--not yet uhuru. Nat Rev Nephrol 2013;9:610-22.

2 Davids MR, Jardine T, Marais N, et al. South African renal registry annual report 2017. African J Nephrol 2019;22:60-71.

3 Okpechi IG, Rayner BL, Swanepoel CR. Peritoneal dialysis in Cape town, South Africa. Perit Dial Int 2012;32:254-60.

4 Zent R, Myers JE, Donald D, et al. Continuous ambulatory peritoneal dialysis: an option in the developing world? Perit Dial Int 1994;14:48-51.

5 Isla RAT, Mapiye D, Swanepoel CR, Tamayo Isla RA, et al. Continuous ambulatory peritoneal dialysis in Limpopo Province, South Africa: predictors of patient and technique survival. Perit Dial Int 2014;34:518-25.

6 Tamayo Isla RA, Ameh OI, Mapiye D, et al. Baseline predictors of mortality among predominantly Rural-Dwelling end-stage renal disease patients on chronic dialysis therapies in Limpopo, South Africa. PLoS One 2016;11:e0156642.

7 Niang A, Cisse MM, Mahmoud SMOM, et al. Pilot experience in Senegal with peritoneal dialysis for end-stage renal disease. Perit Dial Int 2014;34:539-43. 
8 Mahmoud KM, Sheashaa HA, Gheith OA, et al. Continuous ambulatory peritoneal dialysis in Egypt: progression despite handicaps. Perit Dial Int 2010;30:269-73.

9 Davidson B, Crombie K, Manning K, et al. Outcomes and challenges of a PD-First program, a South-African perspective. Perit Dial Int 2018;38:179-86.

10 Li PK-T, Szeto CC, Piraino B, et al. Ispd peritonitis recommendations: 2016 update on prevention and treatment. Perit Dial Int 2016;36:481-508.

11 Moher D, Liberati A, Tetzlaff J, et al. Preferred reporting items for systematic reviews and meta-analyses: the PRISMA statement. PLoS Med 2009;6:e1000097.

12 Moloi MW, Kajawo S, Noubiap JJ, et al. Prevalence of peritonitis and mortality in patients treated with continuous ambulatory peritoneal dialysis (CapD) in Africa: a protocol for a systematic review and meta-analysis. BMJ Open 2018;8:e020464.

13 Abu-Aisha $\mathrm{H}$, Elhassan EA, Khamis $\mathrm{AH}$, et al. Rates and causes of peritonitis in a national multicenter continuous ambulatory peritoneal dialysis program in Sudan: first-year experience. Saudi J Kidney Dis Transpl 2007;18:565-70.

14 Stanifer JW, Jing B, Tolan S, et al. The epidemiology of chronic kidney disease in sub-Saharan Africa: a systematic review and metaanalysis. Lancet Glob Health 2014;2:e174-81.

15 Youmbissi TJ, Lenthe SS, Ngu JL. Peritonitis in a West African CapD programme. Perit Dial Int 1989;9:357.

16 Bekaoui S, Haddiya I, Houti MS, et al. Infectious peritonitis profile in peritoneal dialysis at ibn sina university hospital: a 6-year data report. Int J Nephrol Renovasc Dis 2014;7:323-7.

17 Cisse MM, Hamat I, Gueye S, et al. Peritonitis in patients on peritoneal dialysis: a single-center experience from Dakar. Saudi J Kidney Dis Transpl 2012;23:1061-4.

18 Parsoo I, Seedat YK, Naicker S, et al. An interracial study of continuous ambulatory peritoneal dialysis (CapD) in natal. S Afr Med $J$ 1983;63:403-5.

19 Naiker IP, Naicker S, Botden L, et al. Continuous ambulatory peritoneal dialysis--a South African experience. Int J Artif Organs 1993;16:806-8.

20 Katz IJ, Sofianou L, Hopley M. An African community-based chronic ambulatory peritoneal dialysis programme. Nephrol Dial Transplant 2001:16:2395-400.

21 Naidoo S, Malgas S, Paget G. Peritoneal dialysis in South Africa: a single-center experience. Perit Dial Int 2012;32:S62.

22 Raaijmakers R, Gajjar P, Schröder C, et al. Peritonitis in children on peritoneal dialysis in Cape town, South Africa: epidemiology and risks. Pediatr Nephrol 2010;25:2149-57.

23 Elhassan EAM, Kaballo B, Fedail $\mathrm{H}$, et al. Peritoneal dialysis in the Sudan. Perit Dial Int 2007;27:503-10.

24 Karoui C, Ben Hamida F, Cherif M, et al. [Treatment of uremic patients by automated peritoneal dialysis: study of 78 cases]. Tunis Med 2007;85:225-9.

25 Jellouli Met al. Peritoneal dialysis: experience of the Department of pediatrics of the hospital Charles Nicolle of Tunis. Tunisie Medicale 2016;94:368-74.
26 Lasfar LB, Guedri Y, Zellama D, et al. Long-term clinical outcomes of peritoneal dialysis patients: 10-year experience of a single unit from Tunisia. Saudi J Kidney Dis Transp/ 2019;30:451-61.

27 Krahn MD, Bremner KE, de Oliveira C, et al. Home dialysis is associated with lower costs and better survival than other modalities: a population-based study in Ontario, Canada. Perit Dial Int 2019;39:553-61.

28 Perl J, Fuller DS, Bieber BA, et al. Peritoneal dialysis-related infection rates and outcomes: results from the peritoneal dialysis outcomes and practice patterns study (PDOPPS). Am J Kidney Dis 2020;76:42-53.

29 Strippoli GFM, Tong A, Johnson D, et al. Catheter-related interventions to prevent peritonitis in peritoneal dialysis: a systematic review of randomized, controlled trials. J Am Soc Nephrol 2004; 15:2735-46.

$30 \mathrm{Ye} \mathrm{H}$, Zhou Q, Fan L, et al. The impact of peritoneal dialysis-related peritonitis on mortality in peritoneal dialysis patients. BMC Nephrol 2017; 18:186.

$31 \mathrm{Htay} \mathrm{H}, \mathrm{Cho} \mathrm{Y}$, Pascoe EM, et al. Multicenter registry analysis of center characteristics associated with technique failure in patients on incident peritoneal dialysis. Clin J Am Soc Nephrol 2017:12:1090-9.

32 Yang J-Y, Chen L, Peng Y-S, et al. Icodextrin is associated with a lower mortality rate in peritoneal dialysis patients. Perit Dial Int 2019;39:252-60.

33 Spigolon DN, de Moraes TP, Figueiredo AE, et al. Impact of predialysis care on clinical outcomes in peritoneal dialysis patients. Am J Nephrol 2016;43:104-11.

34 Nkoy AB, Ndiyo YM, Matoka TT, et al. A promising pediatric peritoneal dialysis experience in a resource-limited setting with the support of saving young lives program. Perit Dial Int 2020;40:504-8.

35 Palmer D, Lawton WJ, Barrier C, et al. Peritoneal dialysis for AKI in cameroon: commercial vs locally-made solutions. Perit Dial Int 2018;38:246-50.

36 Ashuntantang G, Osafo C, Olowu WA, et al. Outcomes in adults and children with end-stage kidney disease requiring dialysis in sub-Saharan Africa: a systematic review. Lancet Glob Health 2017;5:e408-17.

37 Levy CS, Mudi A, Venter B, et al. Challenges facing children on chronic peritoneal dialysis in South Africa. Perit Dial Int 2018;38:402-4.

38 McCulloch M, Luyckx VA, Cullis B, et al. Challenges of access to kidney care for children in low-resource settings. Nat Rev Nephrol 2020:45

39 Glenn D, Ocegueda S, Nazareth M, et al. The global pediatric nephrology workforce: a survey of the International pediatric nephrology association. BMC Nephrol 2016;17:83.

40 Manera KE, Johnson DW, Craig JC, et al. Establishing a core outcome set for peritoneal dialysis: report of the SONG-PD (standardized outcomes in Nephrology-Peritoneal dialysis) consensus workshop. Am J Kidney Dis 2020;75:404-12. 